\title{
A Noble-Metal-Free Heterogeneous Photosensitizer-Relay Catalyst Triad That Catalyzes Water Oxidation under Visible Light
}

\author{
T. Gamze Ulusoy Ghobadi, Elif Akhuseyin Yildiz, Muhammed Buyuktemiz, \\ Sina Sadigh Akbari, Derya Topkaya, Ümit Isci, Yavuz Dede,* H. Gul Yaglioglu,* and \\ Ferdi Karadas*
}

\begin{abstract}
An entirely earth-abundant chromophore-relay water oxidation catalyst triad system, which is robust and efficient at neutral $\mathrm{pH}$, is presented. The synthesis involves the coordination of a porphyrin derivative to a bridging $\mathrm{Fe}(\mathrm{CN})_{5}$ group, which is then reacted with Co ions to prepare a covalently linked chromophore-Prussian blue analogue assembly. Light-driven water oxidation studies in the presence of an electron scavenger indicate that the triad is active and it maintains a steady activity for at least three hours. Transient absorption experiments and computational studies reveal that the $\mathrm{Fe}(\mathrm{CN})_{5}$ group is more than a linker as it takes part in electron-transfer and co-operates with porphyrin in the charge separation process.
\end{abstract}

Artificial photosynthesis, which harnesses sunlight to split water, is a chemical transformation of utmost interest. ${ }^{[1]}$ Several innovative photoelectrochemical cells for water splitting have been proposed since the pioneering work by Fujishima and Honda. ${ }^{[2,3]}$ Of these, dye-sensitized photoelectrochemical cells (DS-PECs) utilize covalently coordinated chromophore-water oxidation catalyst (WOC) dyad assemblies $^{[4-6]}$ in an effort to mimic natural photosynthesis. This approach has further been expanded by integrating suitable donor and acceptor units to prepare molecular triads, tetrads, and pentads for efficient charge separation. ${ }^{[7-9]}$ Molecular ruthenium complexes (as photosensitizers and/or WOCs) remain the most widely used despite their high cost and easy decomposition under photocatalytic conditions. ${ }^{[10-19]}$ Although the use of robust heterogeneous assemblies such as oxides could be a promising solution to improve stability, the lack of complete control on the coordination of metal ions in oxide chemistry does not allow the preparation of oxidebased dyads. ${ }^{[20]}$ On the other hand, many cyanide-based assemblies have been prepared previously via a building block approach, similar to the preparation of dyads. ${ }^{[21]}$

Different perspectives of cobalt-based Prussian blue analogues (PBAs) as WOCs have recently been explored by us and other researchers. ${ }^{[2-31]}$ PBAs consist of earth-abundant elements, perform at relatively low overpotentials $(<500 \mathrm{mV}$ for a current density of $\left.1 \mathrm{mAcm}^{-2}\right)$, exhibit exceptional stabilities in a wide $\mathrm{pH}$ range (from 1 to 13), and can operate even with molecular chromophores for light-driven catalysis. ${ }^{[32]}$ Recently, we employed a pentacyanoferrate complex rather than a hexacyanometal precursor to prepare an amorphous PBA with enhanced electrocatalytic activity. ${ }^{[25]}$ The aforementioned study and many others reveal that the ammonia group of $\left[\mathrm{Fe}(\mathrm{CN})_{5}\left(\mathrm{NH}_{3}\right)\right]^{3-}$ complex can be substituted with pyridyl containing organic moieties via a straightforward synthesis. ${ }^{[33,34]}$ Moreover, our preliminary results suggesting that $\left[\mathrm{Fe}(\mathrm{CN})_{5}\right]$ could facilitate the electron transfer between the chromophore and the catalyst encouraged us to use it for the development of a molecular sensitizer-heterogeneous catalyst system. For this purpose, a symmetrically substituted porphyrin derivative, 5,10,15,20-tetra(4-pyridyl)$21 H, 23 H$-porphyrin [TPyP], was selected as the chromophore since it can be produced in bulk scale, it has a high molar absorption coefficient in the visible region, and it contains available pyridyl groups for coordination to pentacyanoiron(II) group.

The amminopentacyanoferrate complex, $\left[\mathrm{Fe}(\mathrm{CN})_{5} \mathrm{NH}_{3}\right]^{3-}$ (Supporting Information, Figure S1), was first reacted with [TPyP] to prepare [Fe-TPyP], which was then reacted with
[*] T. G. Ulusoy Ghobadi, Prof. F. Karadas UNAM - National Nanotechnology Research Center Institute of Materials Science and Nanotechnology Bilkent University, 06800 Ankara (Turkey)

E-mail:karadas@fen.bilkent.edu.tr

T. G. Ulusoy Ghobadi

Department of Energy Engineering

Faculty of Engineering, Ankara University

06830 Ankara (Turkey)

E. Akhuseyin Yildiz, Prof. H. G. Yaglioglu

Department of Engineering Physics, Faculty of Engineering, Ankara University

06100 Ankara (Turkey)

E-mail: gul.yaglioglu@eng.ankara.edu.tr

M. Buyuktemiz, Prof. Y. Dede

Department of Chemistry, Faculty of Science, Gazi University

Teknikokullar, 06500 Ankara (Turkey)
E-mail: dede@gazi.edu.tr

Prof. D. Topkaya

Department of Chemistry, Faculty of Sciences, Dokuz Eylul University Tınaztepe Campus, Izmir (Turkey)

Prof. Ü. İsci

Department of Chemistry, Gebze Technical University 41400 Kocaeli (Turkey)

S. Sadigh Akbari, Prof. F. Karadas

Department of Chemistry, Faculty of Science, Bilkent University 06800 Ankara (Turkey)

(1) Supporting information and the ORCID identification number(s) for (D) the author(s) of this article can be found under: https://doi.org/10.1002/anie.201811570. 
[TPyP]
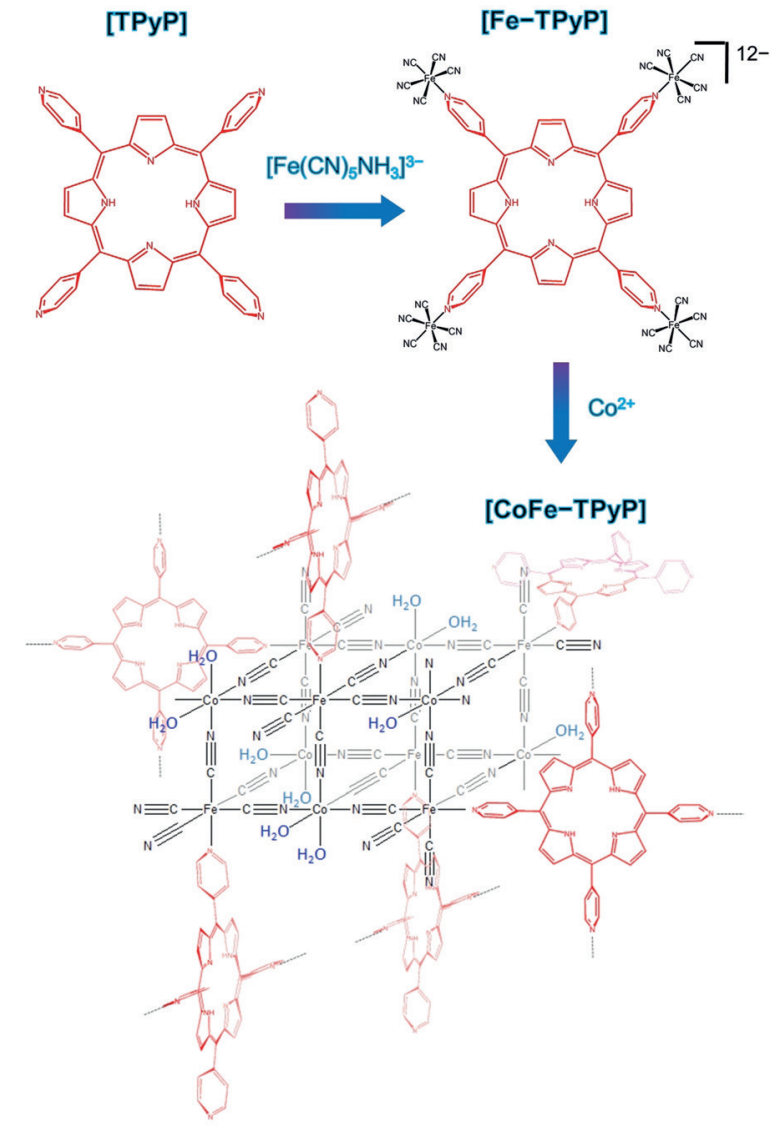

Scheme 1. General synthesis and molecular structures of [TPyP], [FeTPyP], and [CoFe-TPyP].

$\mathrm{Co}^{2+}$ ions to prepare the triad, [CoFe-TPyP] (Scheme 1). An assembly, in which a molecular chromophore is coordinated to a heterogeneous cyanide-based catalyst, was prepared with this synthetic route. The synthetic pathway adopts a molecular bottom-up approach similar to the ones previously reported for chromophore-catalyst assemblies, ${ }^{[7-19]}$ while it differs significantly from those by the formation of a heterogeneous assembly in the final step.

The ${ }^{1} \mathrm{H}$ NMR spectrum of [Fe-TPyP] exhibits the characteristic chemical shifts of $[\mathrm{TPyP}]$, which indicates that the porphyrin ring is still intact and each pyridyl group is coordinated to iron sites (Supporting Information, Figure S2). Infrared studies also confirm the complexation and the formation of a Prussian blue network (Supporting Information, Figure S3). XPS spectra of $\mathrm{N} 1 \mathrm{~s}$ and $\mathrm{Fe} 2 \mathrm{p}$ bands (Supporting Information, Figures S4-S6 and Table S1) are also in good agreement with the expected structures. ${ }^{[35]}$ The corresponding SEM-EDX elemental mapping reveals the homogenous distribution of the elemental species (Supporting Information, Figures S7 and S8) in [Fe-TPyP] and [CoFeTPyP]. The energy-dispersive X-ray spectroscopy (EDS) of [CoFe-TPyP] (Supporting Information, Figure S9) also reveals a stoichiometric ratio of 3:2 (Co:Fe), which is in line with the expected formula based on charge balance.

For comparison, [ZnFe-TPyP] was also prepared and characterized with Infrared, XPS, and SEM studies (Supporting Information, Figures S10 and S11). The cyclic voltammo- gram (CV) of [CoFe-TPyP] modified FTO electrode exhibits an irreversible peak at high anodic potentials corresponding to catalytic water oxidation process. This feature is absent in the $\mathrm{CV}$ of [ZnFe-TPyP] modified FTO electrode, which indicates that water is oxidized only at cobalt sites (Supporting Information, Figure S12).

Characterization studies and the unique coordination mode of the cyanide ligand suggest the presence of randomsized PB structures with limited dimensionalities owing to surrounding molecular porphyrin rings in [CoFe-TPyP] (note that the compound has an amorphous nature; Supporting Information, Figure S13). The coordination of each Fe site to a porphyrin macrocycle reduces the dimensionality of $\mathrm{PB}$ structures significantly, which in return yields cobalt sites coordinated to at least one $\mathrm{H}_{2} \mathrm{O}$ molecule that is essential for water oxidation.

Photocatalytic $\mathrm{O}_{2}$ evolution profile of [CoFe-TPyP] in the presence of a sacrificial electron acceptor $\left(\mathrm{K}_{2} \mathrm{~S}_{2} \mathrm{O}_{8}\right)$ reveals a steady increase during a $1 \mathrm{~h}$ experiment (Figure 1 ). The

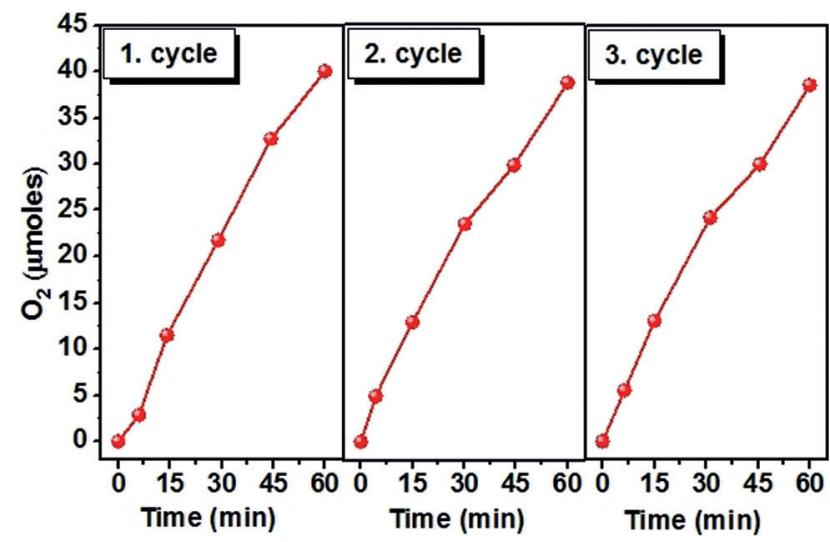

Figure 1. Photocatalytic oxygen evolution by [CoFe-TPyP] (10 mg) and $\mathrm{K}_{2} \mathrm{~S}_{2} \mathrm{O}_{8}(20 \mathrm{~mm})$ in $\mathrm{pH} 7,50 \mathrm{~mm}$ phosphate buffer solution. Same batch was used in each cycle.

curve yields a turnover frequency of $3.2 \times 10^{-4} \mathrm{~s}^{-1}\left(1.2 \mathrm{~h}^{-1}\right)$, which is similar to the one obtained with PBAs in the presence of a $\mathrm{Ru}(\mathrm{bpy})_{3}{ }^{2+} / \mathrm{S}_{2} \mathrm{O}_{8}{ }^{2-}$ system and much higher than the one obtained when [TPyP] was mixed with a cobalthexacyanoferrate (Supporting Information, Figure S14). ${ }^{[32]}$ A similar profile was obtained for three cycles of the same batch, which indicates that [CoFe-TPyP] is stable during photocatalytic water oxidation process. This is also confirmed with comprehensive characterization studies performed on the post-catalytic powder sample (Supporting Information, Figures S15-S17). Overall, photocatalytic tests confirm that porphyrin and $\mathrm{PB}$ structures collaborate for light-assisted water-oxidation catalysis, which could be due to an efficient pathway for electron transfer between the chromophore and the catalytic cobalt sites. This mechanism has been investigated by computational and femtosecond transient absorption (TA) studies.

Previously, we have explored the electronic structure details of similar Co sites used as WOCs and have shown that it is critical to oxidize the Co site and increase its electro- 
philicity to enhance the nucleophilic attack of water. ${ }^{[26,36]}$ The reactivity parameters in the current study suggest a similar Co centered $\mathrm{O}-\mathrm{O}$ bond formation under photocatalytic conditions. Moreover, [Fe-TPyP] moiety in the [CoFe-TPyP] system is presumably the photochemically active species and the role of the Co centers is similar to what we have previously reported. ${ }^{[26,36]}$ We therefore studied the electronic structure and excitation characteristics of [CoFe-TPyP] and [Fe-TPyP] with density functional theory (DFT). For simplicity we discuss the excitation motif of [Fe-TPyP] below and emphasize that [CoFe-TPyP] computations yield exactly the same results (Supporting Information, Figures S18-S20). Owing to the complexity in reliable computation of the electronic structures of multiple high spin Co centers, electron transfer dynamics of [CoFe-TPyP] were studied with TA spectra.

The ground state of $[\mathrm{Fe}-\mathrm{TPyP}]$ is found to be a closed shell singlet (Supporting Information, Table S2) with four electronically identical Fe centers having low spin configurations (Supporting Information, Table S3) as expected for Fe in strong ligand environment. From the frontier orbitals $\mathrm{HOMO}$ is comprised of Fe-d and porphyrin- $\pi$ orbitals. Two other high lying occupied orbitals involved in the excitation are of porphyrin $\pi$ and $\mathrm{Fe}-\mathrm{d}+$ porphyrin- $\pi$ in character (Figure 2; Supporting Information, Figure S20). These three molecular orbitals (MOs) delocalized on the porphyrin ring and $\mathrm{Fe}$ center are the domain for the excitation.

The two lowest-lying unoccupied MOs, both of porphyrin$\pi^{*}$ character, are the degenerate pair of LUMO and $\mathrm{LUMO}+1$. The calculated excitation motif suggests that an electron hosted in a hybrid $\mathrm{Fe}-\mathrm{d}+$ porphyrin- $\pi$ orbital is
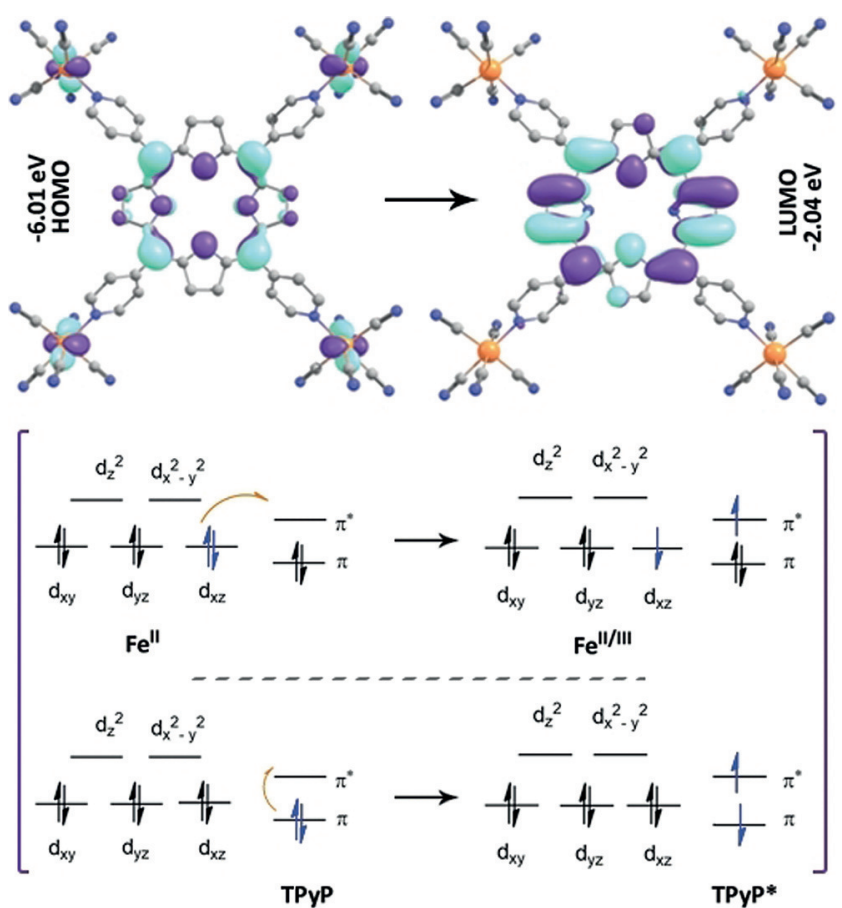

Figure 2. TD-DFT excitation behavior for [Fe-TPyP] at UB3LYP/def2-TZV level of theory. A hybrid Fe- $d+$ porphyrin- $\pi \rightarrow$ porphyrin- $\pi *$ state is generated. transferred to porphyrin based $\pi^{*}$ orbital upon irradiation. Thus, $\mathrm{Fe}(\mathrm{CN})_{5}$ fragment is partly oxidized during the excitation and an internal charge transfer state with one unpaired electron on $\mathrm{Fe}$ and one on the porphyrin is accessed. Such an excited state of charge transfer nature can easily hop to the triplet surface (within only $0.1 \mathrm{eV}$; Supporting Information, Tables S2 and S4) and live long enough to further oxidize the Co-centers. Excitations and proton coupled electron transfer events studied for the [CoFe-TPyP] shed light on the nature of the intermediates (Supporting Information, Figures S20 and S21). Comparison with the [ZnFeTPyP] system (Supporting Information, Figure S22) reveal that the $\mathrm{Zn}$ center does not possess the key electronic structure (Supporting Information, Table S6) to carry the $\mathrm{O}^{-}$ $\mathrm{O}$ bond formation. (A detailed computational study about the electronic structure of the intermediates and their transformations will be reported as a subsequent work.) The effect of cobalt sites on the electron transfer is supported by the transient absorption studies (see below).

Quantum-chemical calculations thus suggest that: 1) Fecenters are involved in donating electrons and porphyrin is an electron acceptor; 2) this internal charge transfer repositions the electrons in two distinct fragments of the system and decreases the likelihood of charge recombination, thereby allowing the excited state to live long enough and to undergo other important electronic changes; 3) the electron-transfer yields an MLCT state; and 4) the internally oxidized Fe centers act as holes to further oxidize Co sites, an essential feature for $\mathrm{O}-\mathrm{O}$ bond formation at the Co site as shown previously. ${ }^{[26]}$ These results are also verified by steady state absorption (SSA), fluorescence (FL), and transient absorption (TA) measurements.

SSA graphs of the investigated compounds show typical characteristic of porphyrins, as shown in the Supporting Information, Figure S23. ${ }^{[37]}$ FL measurements are given in the Supporting Information, Figures S24 and S25.

TA spectra for [TPyP], [Fe-TPyP], and [CoFe-TPyP] at zero time delay and decay traces of the bleach signals at $424 \mathrm{~nm}$ probe wavelength are given in Figure 3 along with the

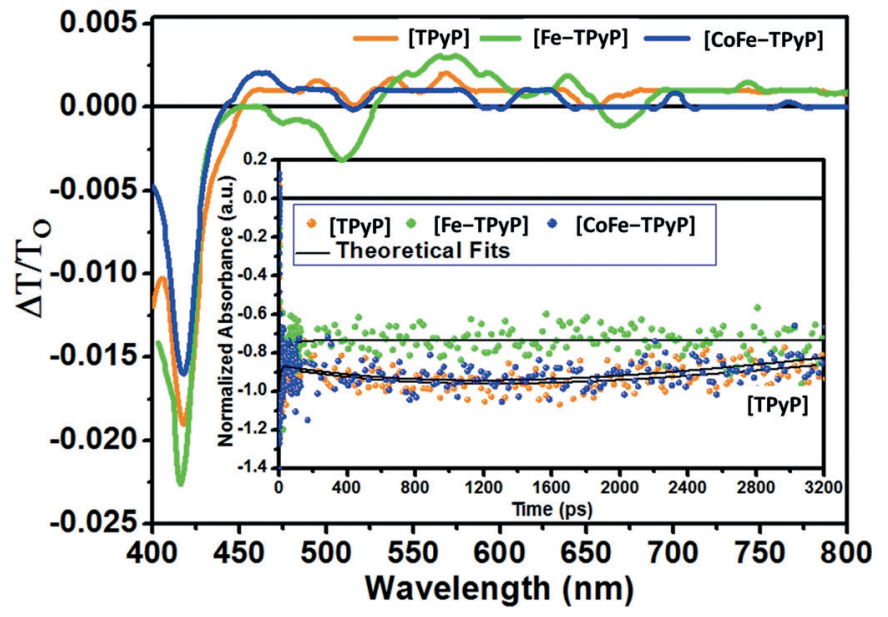

Figure 3. Transient absorption spectra at zero time delay and time evolution of the bleach signals at $424 \mathrm{~nm}$ wavelength for [TPyP], [FeTPyP], and [CoFe-TPyP] compounds. 
a

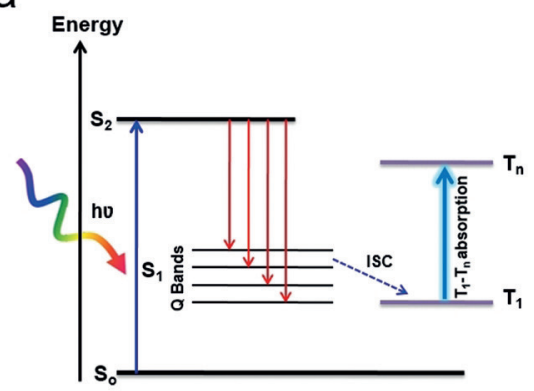

[TPyP] b

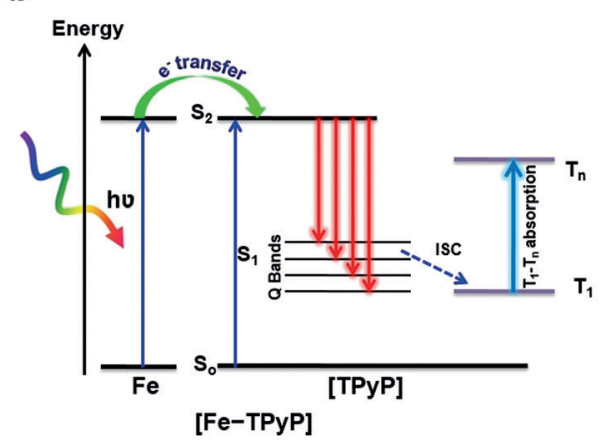

C

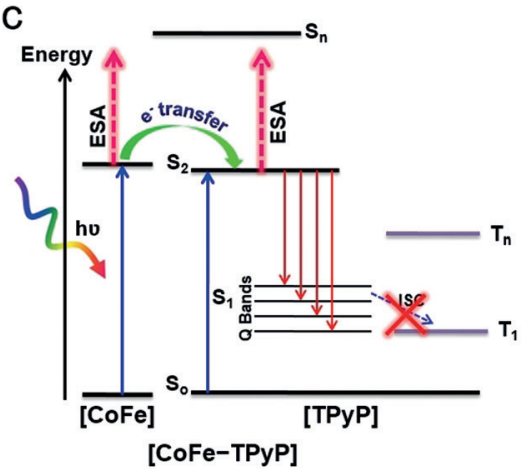

Scheme 2. Illustration of the energy diagram for a) [TPyP], b) [Fe-TPyP], and c) [CoFe-TPyP] compounds.

proposed electron transfer mechanism (Scheme 2). [TPyP] shows typical features including a characteristic ground state bleaching and a stimulated emission around $420 \mathrm{~nm}, \mathrm{Q}$ bands bleaching around 520 and $650 \mathrm{~nm}$, and $\mathrm{T}_{1}-\mathrm{T}_{\mathrm{n}}$ absorption around $440 \mathrm{~nm}$ developing by intersystem crossing (ISC) process after $48 \mathrm{ps}$ time delay (Supporting Information, Figures S26 and S27). Although TA measurement of [FeTPyP] is similar to that of [TPyP], it shows enhanced bleaching of $\mathrm{Q}$ bands as well as $\mathrm{T}_{1}-\mathrm{T}_{\mathrm{n}}$ absorption band (Supporting Information, Figures S28 and S29). ${ }^{[38]}$ These data show the electron transfer from Fe-center to porphyrin as supported by the TD-DFT calculations (Figure 2; Supporting Information, Figure S30). On the other hand, decay trace of $430 \mathrm{~nm}$ bleach signal for [Fe-TPyP] exhibits a longer lifetime (from pumped state to ground state) than that of [TPyP], which is required for efficient photocatalytic process (Supporting Information, Table S7 and Figure S31). In the case of [CoFe-TPyP], excited state absorption with long lifetime around $430 \mathrm{~nm}$ appears at zero time delay suggesting that this is not a $\mathrm{T}_{1}-\mathrm{T}_{\mathrm{n}}$ absorption (Supporting Information, Figures S32, S33; Scheme 2). ${ }^{[39]}$ This profile also implies that the deactivation pathway of [Fe-TPyP] excited state is altered with the presence of Co-sites due to further electron transfer, which yields a longer living [CoFe-TPyP] state. TA measurements thus lead to the conclusion that the Co centers are internally oxidized with the assistance of $\mathrm{Fe}(\mathrm{CN})_{5}$ group, hence the photocatalytic water oxidation utilizes the $[\mathrm{Fe}$ TPyP] moiety as the photosensitizer and Co sites as the catalytic centers.

In conclusion, an entirely earth-abundant cyanide-based chromophore-relay-catalyst triad system for light-driven water oxidation was reported for the first time by engaging cyanide chemistry with the dyad concept. The reported assembly is genuine, due not only to the simplicity of its synthesis but also to the bifunctionality of each of its components. The porphyrin fragment is both a chromophore and a capping ligand for reducing the dimensionality of $\mathrm{PB}$ structures, thus, increasing the number of active catalytic sites. Transient absorption measurements and computational studies show that $\left[\mathrm{Fe}(\mathrm{CN})_{5}\right]$ moiety serves both as a robust linker and a relay group that facilitates the electron transfer from the catalyst to the chromophore. Co-sites are essential for catalytic water oxidation. They also play a critical role in the formation of a stable heterogeneous assembly. Overall, this proof-of-concept study indicates that cyanide-based systems could be the key element for the development of earth abundant, robust, and efficient dye-sensitized photoanodes. The modular and versatile $\mathrm{Fe}(\mathrm{CN})_{5}$ chemistry is further explored in our labs by introducing other chromophores to generalize the concept of photocatalytic water oxidation with cyanide-based assemblies.

\section{Acknowledgements}

This work is supported by the Scientific and Technological Research Council of Turkey (TUBITAK), grant number 215Z249. F.K. and Y.D. thank TÜBA-GEBİP for young investigator awards and BAGEP for a young scientist award.

\section{Conflict of interest}

The authors declare no conflict of interest.

Keywords: dye-sensitization - porphyrins - Prussian blue . water oxidation $\cdot$ water splitting

How to cite: Angew. Chem. Int. Ed. 2018, 57, 17173-17177 Angew. Chem. 2018, 130, 17419-17423

[1] D. G. Nocera, Acc. Chem. Res. 2012, 45, 767-776.

[2] A. Fujishima, K. Honda, Nature 1972, 238, 37-38.

[3] M. G. Walter, E. L. Warren, J. R. McKone, S. W. Boettcher, Q. Mi, E. A. Santori, N. S. Lewis, Chem. Rev. 2010, 110, 6446-6473.

[4] Z. Yu, F. Li, L. Sun, Energy Environ. Sci. 2015, 8, 760-775.

[5] D. L. Ashford, M. K. Gish, A. K. Vannucci, M. K. Brennaman, J. L. Templeton, J. M. Papanikolas, T. J. Meyer, Chem. Rev. 2015, 115, 13006-13049.

[6] S. Berardi, S. Drouet, L. Francàs, C. Gimbert-Suriñach, M. Guttentag, C. Richmond, T. Stoll, A. Llobet, Chem. Soc. Rev. 2014, 43, $7501-7519$.

[7] M. Yamamoto, J. Föhlinger, J. Petersson, L. Hammarström, H. Imahori, Angew. Chem. Int. Ed. 2017, 56, 3329-3333; Angew. Chem. 2017, 129, 3377-3381.

[8] L. Favereau, A. Makhal, Y. Pellegrin, E. Blart, J. Petersson, E. Göransson, L. Hammarström, F. Odobel, J. Am. Chem. Soc. 2016, 138, 3752-3760. 
[9] T. Schlotthauer, R. Schroot, S. Glover, L. Hammarström, M Jäger, U. S. Schubert, Phys. Chem. Chem. Phys. 2017, 19, $28572-$ 28578.

[10] M. K. Brennaman, R. J. Dillon, L. Alibabaei, M. K. Gish, C. J. Dares, D. L. Ashford, R. L. House, G. J. Meyer, J. M. Papanikolas, T. J. Meyer, J. Am. Chem. Soc. 2016, 138, 13085-13102.

[11] F. Li, K. Fan, B. Xu, E. Gabrielsson, Q. Daniel, L. Li, L. Sun, J. Am. Chem. Soc. 2015, 137, $9153-9159$

[12] F. Li, K. Fan, L. Wang, Q. Daniel, L. Duan, L. Sun, ACS Catal. 2015, 5, 3786-3790

[13] L. Li, L. Duan, Y. Xu, M. Gorlov, A. Hagfeldt, L. Sun, Chem. Commun. 2010, 46, 7307-7309.

[14] H. Li, F. Li, B. Zhang, X. Zhou, F. Yu, L. Sun, J. Am. Chem. Soc. 2015, 137, $4332-4335$.

[15] B. D. Sherman, Y. Xie, M. V. Sheridan, D. Wang, D. W. Shaffer, T. J. Meyer, J. J. Concepcion, ACS Energy Lett. 2017, 2, 124-128.

[16] B. D. Sherman, M. V. Sheridan, K. Wee, S. L. Marquard, D. Wang, L. Alibabaei, D. L. Ashford, T. J. Meyer, J. Am. Chem. Soc. 2016, 138, 16745-16753.

[17] L. Alibabaei, R. J. Dillon, C. E. Reilly, M. K. Brennaman, K. Wee, S. L. Marquard, J. M. Papanikolas, T. J. Meyer, ACS Appl. Mater. Interfaces 2017, 9, 39018-39026.

[18] M. Yamamoto, Y. Nishizawa, P. Chábera, F. Li, T. Pascher, V. Sundström, L. Sun, H. Imahori, Chem. Commun. 2016, 52, $13702-13705$

[19] M. Yamamoto, L. Wang, F. Li, T. Fukushima, K. Tanaka, L. Sun, H. Imahori, Chem. Sci. 2016, 7, 1430-1439.

[20] J. T. Kirner, R. G. Finke, ACS Appl. Mater. Interfaces 2017, 9 , $27625-27637$

[21] M. Shatruk, C. Avendano, K. R. Dunbar, Prog. Inorg. Chem. 2009, 56, 155-334.

[22] L. Han, P. Tang, A. Reyes-Carmona, B. Rodriguez-Garcia, M. Torrens, J. R. Morante, J. Arbiol, J. R. Galán-Mascarós, J. Am. Chem. Soc. 2016, 138, 16037-16045.

[23] S. Pintado, S. Goberna-Ferrón, E. C. Escudero-Adán, J. R. Galán-Mascarós, J. Am. Chem. Soc. 2013, 135, 13270-13273.
[24] Y. Yamada, K. Oyama, R. Gates, S. Fukuzumi, Angew. Chem. Int. Ed. 2015, 54, 5613-5617; Angew. Chem. 2015, 127, 57055709.

[25] M. Aksoy, S. V. K. Nune, F. Karadas, Inorg. Chem. 2016, 55, $4301-4307$.

[26] E. P. Alsaç, E. Ülker, S. V. K. Nune, Y. Dede, F. Karadas, Chem. Eur. J. 2018, 24, 4856-4863.

[27] F. S. Hegner, D. Cardenas-Morcoso, S. Giménez, N. López, J. R. Galán-Mascarós, ChemSusChem 2017, 10, 4552-4560.

[28] F. S. Hegner, I. Herraiz-Cardona, D. Cardenas-Morcoso, N. López, J. R. Galán-Mascarós, S. Gimenez, ACS Appl. Mater. Interfaces 2017, 9, 37671-37681.

[29] Y. Yamada, K. Oyama, T. Suenobu, S. Fukuzumi, Chem. Commun. 2017, 53, 224-232.

[30] Y. Aratani, T. Suenobu, K. Ohkubo, Y. Yamada, S. Fukuzumi, Chem. Commun. 2017, 53, 3473-3476.

[31] Y. Aratani, K. Oyama, T. Suenobu, Y. Yamada, S. Fukuzumi, Inorg. Chem. 2016, 55, 5780-5786.

[32] S. Goberna-Ferrón, W. Y. Hernández, B. Rodríguez-García, J. R. Galán-Mascarós, ACS Catal. 2014, 4, 1637-1641.

[33] D. H. Macartney, Rev. Inorg. Chem. 1988, 9, 101-152.

[34] K. Szaciłowski, Z. Stasicka, Coord. Chem. Rev. 2002, 229, 17-26.

[35] J. R. Eskelsen, Y. Qi, S. Schneider-Pollack, S. Schmitt, K. W. Hipps, U. Mazur, Nanoscale 2014, 6, 316-327.

[36] E. A. Turhan, S. V. K. Nune, E. Ülker, U. Şahin, Y. Dede, F. Karadas, Chem. Eur. J. 2018, 24, 10372-10382.

[37] Y. Venkatesh, S. Karthik, Y. Rajesh, M. Mandal, A. Jana, N. D. P. Singh, Chem. Asian J. 2016, 11, 3482-3486.

[38] R. N. Sampaio, M. M. Silva, A. A. Batista, N. M. B. Neto, J. Photochem. Photobiol. A 2016, 315, 98-106.

[39] A. M. López, M. Natali, E. Pizzolato, C. Chiorboli, M. Bonchio, A. Sartorel, F. Scandola, Phys. Chem. Chem. Phys. 2014, 16, $12000-12007$

Manuscript received: October 8, 2018

Accepted manuscript online: November 5, 2018

Version of record online: December 5, 2018 